\title{
Effect of Agro-ecological Zone, Age, and Sex on Prevalence and Intensity of Gastrointestinal Parasites in Donkeys in Maseru District, Lesotho
}

\author{
Masara Elizabeth Nts'aoana*, Setsumi Mots'oene Molapo, and Paseka Kompi \\ The Department of Animal Science, Faculty of Agriculture, The National University of Lesotho, PO Roma 180, Maseru, Lesotho \\ *Corresponding author's Email: entsaoana@gmail.com; (DORCiD: 0000-0001-5942-720X
}

\begin{abstract}
Gastrointestinal parasites are considered to be silent killers of animals. The objective of the current study was to determine the effect of the agro-ecological zone, age, and sex on the parasite prevalence and fecal egg/oocyst count in donkeys residing in Lesotho. A total number of 720 fecal samples were collected rectally from 120 indigenous donkeys that were randomly selected from the highlands, foothills, and lowlands of Maseru district, Lesotho. The fecal samples were collected every two months for one year and examined using the floatation technique. The overall prevalence for nematodes, coccidia, and cestodes in donkeys were $87.78 \%, 4.31 \%$, and $1.53 \%$, respectively. The highest nematode prevalence and intensity were detected in the donkeys of highlands. The coccidian infection was lower in the lowlands while cestodes infection was more prevalent in the foothills. Donkey's age had an impact on the nematode fecal egg load but did not affect the prevalence of nematodes in donkeys. Age did not significantly affect the prevalence and fecal egg/oocyst count of cestodes and coccidia. Male donkeys had a higher prevalence and fecal egg count of cestodes. In conclusion, the nematodes were found to be the major gastrointestinal parasites of donkeys in the Maseru district. Therefore, there is a need to design a sustainable strategy aimed at controlling the gastrointestinal parasites in donkeys.
\end{abstract}

Keywords: Agro-ecological zone, Eimeria, Fecal egg count, Helminth, Prevalence

\section{INTRODUCTION}

In many countries, equines have a great contribution to the national economy; however, gastrointestinal parasites (GIPs) are the major constraints that hinder their probable output (Enigidaw et al., 2015). These parasites hinder the maximum working capacity of donkeys (Nakayima et al., 2017). The poor nutritional and immune status of equines also makes the equine to be susceptible to parasitic diseases, which negatively influences their health and working performance (Zerihun et al., 2011; Belay et al., 2016). Tesfu et al. (2014) observed that among the helminths, nematodes, especially strongyles, are one of the most common and prevalent GIPs in donkeys. Factors such as temperature and moisture provide a favorable environment for the development of larvae to the infective stage which is ingested during animal grazing (Saeed et al., 2019). The infection occurs from the ingestion of infective larvae or eggs during grazing (Andarge et al., 2017). Takele and Nibret, (2013) stated that open grazing promotes ingestion of the helminth eggs. According to Upjohn et al. (2010), the intensity of infection can be affected by climatic conditions, grazing practices, and anthelmintic use. Waqas et al. (2015) indicated a high likelihood of GIP infection occurrence to grazing equines. In addition, Molla et al. (2015) reported that communal grazing serves as a favorable factor for the survival of strongyles.

Tedla and Abichu (2018) indicated that lack of sufficient veterinary services and poor management of equines contribute to higher parasitic infections. Donkeys depend on rangelands for feeding, therefore, the chance of being infected with parasites is very high. In Lesotho, owners do not follow appropriate animal health management practices in the donkey population (Demelash et al., 2016), leading to high incidences of parasite infections. In addition, there is a lack of information on the prevalence of GIPs among donkeys in Lesotho. Therefore, the objective of the current study was to determine the effect of Agro-ecological Zone (AEZ), age, and sex on the prevalence and intensity of GIP infections in donkeys. The findings of the present study would help donkey owners and other relevant stakeholders to design the holistic deworming strategy for donkeys. The welfare of donkeys would be enhanced and hence the lives of the rural communities would improve due to the enhanced performance of donkeys.

\section{MATERIALS AND METHODS}

\section{Ethical approval}

The scientific and ethics committee of the Department of Animal Science of the National University of Lesotho approved the study protocol. The use of animals was in accordance with the international animal welfare standards laid 
down in the 1964 Declaration of Helsinki and its later amendments.

\section{Study area}

The study was conducted for 12 months from May 2018 to April 2019 in the three AEZs of Maseru district in Lesotho, including the lowlands, foothills, and highlands named Koro-koro, Matsieng, and Marakabei, respectively. The lowlands have an altitude ranging from 1500-1800 m above sea level, foothills are in the middle between 1800-2200 m above sea level and it covers $10-15 \%$ of the total area while the highlands covers over $2 / 3$ of the country and rises to the elevation of 2200-3000 $\mathrm{m}$ above the sea level (FAO, 1996). The lowlands have the annual rainfall ranging from 600-900 $\mathrm{mm}$, foothills between $900-1000 \mathrm{~mm}$ while $1000-1300 \mathrm{~mm}$ is experienced in the highlands. The temperatures vary from 11 to $30{ }^{\circ} \mathrm{C}$ (Olaleye et al., 2016).

\section{Sample size and fecal egg counting}

A total number of 120 indigenous donkeys were randomly selected from the three AEZs. The selection of villages in the three AEZs was done through the help of Agricultural Technical Officers. The data was collected with respect to AEZ, sex, and age. A total number of 40 donkeys were selected per AEZ, consisting of 20 males and 20 females, and 5 young and 15 adults were selected as experimental units from each gender group. The age estimation of donkeys was performed through dentition whereby the young animals consisted of the donkeys less than two years old while adults were defined as those above two years old.

A total number of 720 fecal samples was directly collected rectally from 120 indigenous donkeys with disposable gloves into airtight bottles. The fecal samples were collected every two months for a period of one year (six samples per animal). The bottles containing samples were kept in the cool box to prevent hatching the eggs before Fecal Egg Counting (FEC), then examined by using the floatation technique (Zajac and Conboy, 2012). The collected fecal samples were refrigerated in the Animal Science Laboratory and the laboratory analyses were done within 48 hours. In the laboratory, each fecal sample weighing $4 \mathrm{~g}$ was thoroughly mixed with $56 \mathrm{~mL}$ of sodium chloride (floatation solution). The solution was sieved into the beaker and a few drops of amyl alcohol were added to treat the bubbles. The pipette was used to draw some milliliters of the solution to fill the two chambers of the McMaster slide and then viewed under a light microscope (Olympus, Japan). All eggs/oocyst of GIPs were counted and identified based on their morphology. The number of eggs/oocysts per grams of feces was calculated using the following formula (Nakayima et al., 2017):

Fecal egg/oocyst count $=($ number of eggs/oocysts in chamber $1+$ number of eggs/oocysts in chamber 2$) \times 50$

The prevalence of GIPs was calculated as follows:

Prevalence $=[$ (number of positive samples) $/($ number of examined samples $)] \times 100$

\section{Statistical analysis}

The Statistical Package for Social Sciences (SPSS, version 16.0) was used for data analysis. The general linear model was used to evaluate the effect of AEZ, sex, and age on the GIPs prevalence and fecal egg/oocyst count in donkeys. The data was also subjected to binary logistic regression under General Estimating Equations (GEE) to observe the likelihood of change in prevalence. The GEE was also used to analyze fecal egg/oocyst count data adopting a negative binomial regression model expressing the results in terms of Beta Exponential (in percentages). Based on Duncan's multiple range test, the confidence interval was held at $95 \%$ and p-value less than 0.05 was considered statistically significant.

\section{RESULTS}

\section{Overall prevalence of gastrointestinal parasites infection}

The results from the examination of fecal samples indicated that donkeys were positive for different GIPs. The identified fecal eggs/oocysts were from nematodes, cestodes, coccidia with the prevalence of $87.78 \%, 1.53 \%$, and $4.31 \%$, respectively (Table 1).

\section{Prevalence and intensity of gastrointestinal parasites infection in different agro-ecological zones}

Nematode eggs were most observed in donkeys in the study areas (Table 2). The highest prevalence of nematodes was observed in donkeys reared in the highlands (90.40\%), followed by lowlands (89.20\%), and foothills (83.80\%). However, the difference was not significant between the donkeys in the highlands and lowlands $(\mathrm{p}>0.05)$. However, the fecal egg count in donkeys in the highlands was significantly higher than those kept in the lowlands $(p<0.05)$. In the foothills, the number of donkeys infected with nematodes was significantly lower than those in the highlands $(\mathrm{p}<0.05)$, but the fecal egg count was not affected by AEZs. In the case of coccidia, the prevalence was higher in donkeys found in the highlands $(6.20 \%)$ than those in the foothills $(4.20 \%)$ but not statistically significant $(\mathrm{p}>0.05)$. The prevalence of 
coccidia in donkeys in the lowlands $(2.50 \%)$ was not statistically different from those in the foothills but significantly different $(\mathrm{p}<0.05)$ from donkeys found in the highlands. The difference in fecal oocyst counts was non-significant across the three AEZs (Table 2). There was a non-significant difference ( $p>0.05)$ in the prevalence and intensity of cestode infection among donkeys in different agro-ecological zones (Table 2).

\section{Prevalence and intensity of gastrointestinal parasites infection in different age groups}

As presented in Table 3, there was no significant difference $(p>0.05)$ in the prevalence of gastrointestinal nematodes between young and adult donkeys while the fecal egg count was significantly different $(p<0.05)$ between these two groups. The adult donkeys were more heavily infected with gastrointestinal nematodes. Regarding cestodes and coccidia, the obtained results indicated that the prevalence and intensity of infection did not differ significantly in adult and young donkeys ( $\mathrm{p}>0.05$, Table 3$)$.

\section{Prevalence and intensity of gastrointestinal parasites infection according to sex in donkeys}

As presented in Table 4, the prevalence and intensity of nematode infection were higher in the female donkeys than male donkeys but the effect was not statistically significant $(p>0.05)$. The prevalence of coccidia infection was higher in male donkeys but had a lower fecal oocyst count than female donkeys. However, the differences were insignificant ( $p$ $>0.05$, Table 4). The cestodes prevalence and fecal egg count were significantly higher in males than those in females ( $\mathrm{p}$ $<0.05$, Table 4).

Table 1. Prevalence of gastrointestinal parasites in fecal samples collected from 120 indigenous donkeys in Maseru District, Lesotho, based on fecal egg/oocyst counts.

\begin{tabular}{lccc}
\hline Gastrointestinal parasites & Number of samples examined & Number of positive samples & Prevalence (\%) \\
\hline Nematodes & 720 & 632 & 87.78 \\
Coccidia & 720 & 31 & 4.31 \\
Cestodes & 720 & 11 & 1.53 \\
\hline
\end{tabular}

Table 2. Effect of the ago-ecological zone on the gastrointestinal parasites prevalence and fecal egg/oocyst count in donkeys in Maseru District, Lesotho.

\begin{tabular}{ll|c|c|cc}
\hline \multirow{2}{*}{ Agro-ecological zone } & \multicolumn{2}{|c|}{ Prevalence } & \multicolumn{2}{c}{ Fecal egg/oocyst count } \\
\cline { 3 - 6 } & Lowlands & $\%$ & Standard error & EMM & Standard error \\
\hline \multirow{2}{*}{ Nematodes } & Foothills & $89.20^{\mathrm{ab}}$ & 0.020 & $528.12^{\mathrm{a}}$ & 40.609 \\
& Highlands & $83.80^{\mathrm{a}}$ & 0.024 & $639.17^{\mathrm{ab}}$ & 36.843 \\
\hline \multirow{3}{*}{ Coccidia } & $90.40^{\mathrm{b}}$ & 0.019 & $673.96^{\mathrm{b}}$ & 51.511 \\
& Lowlands & $2.50^{\mathrm{a}}$ & 0.010 & $4.79^{\mathrm{a}}$ & 2.163 \\
& Foothills & $4.20^{\mathrm{ab}}$ & 0.0 .13 & $5.00^{\mathrm{a}}$ & 2.259 \\
\multirow{3}{*}{ Cestodes } & $6.20^{\mathrm{b}}$ & 0.016 & $6.67^{\mathrm{a}}$ & 2.108 \\
& Highlands & $0.80^{\mathrm{a}}$ & 0.060 & $1.04^{\mathrm{a}}$ & 0.843 \\
& Lowlands & $2.10^{\mathrm{a}}$ & 0.090 & $2.92^{\mathrm{a}}$ & 1.574 \\
\hline
\end{tabular}

${ }^{\mathrm{ab}}$ Means within a column with a common superscript do not differ significantly (p>0.05). EMM: Estimated Marginal Means. Exp.B: Exponential Beta.

Table 3. Effect of age group on the gastrointestinal parasites prevalence and fecal egg/oocyst count in donkeys in Maseru District, Lesotho.

\begin{tabular}{ll|c|c|c|c}
\hline \multirow{2}{*}{ Age } & \multicolumn{2}{|c|}{ Prevalence } & \multicolumn{2}{c}{ Fecal egg/oocyst count } \\
\cline { 3 - 6 } & & $\%$ & Standard error & EMM & Standard error \\
\hline \multirow{2}{*}{ Nematodes } & Young $(<2 \mathrm{y})$ & $86.70^{\mathrm{a}}$ & 0.024 & $492.22^{\mathrm{a}}$ & 27.365 \\
& Adults $(>2 \mathrm{y})$ & $88.10^{\mathrm{a}}$ & 0.014 & $654.26^{\mathrm{b}}$ & 31.444 \\
\hline \multirow{2}{*}{ Coccidia } & Young $(<2 \mathrm{y})$ & $4.40^{\mathrm{a}}$ & 0.015 & $6.67^{\mathrm{a}}$ & 2.528 \\
& Adults $(>2 \mathrm{y})$ & $4.30^{\mathrm{a}}$ & 0.090 & $5.09^{\mathrm{a}}$ & 1.450 \\
\hline \multirow{2}{*}{ Cestodes } & Young $(<2 \mathrm{y})$ & $0.00^{\mathrm{a}}$ & 0.090 & $0.00^{\mathrm{a}}$ & 1.295 \\
& Adults $(>2 \mathrm{y})$ & $2.00^{\mathrm{a}}$ & 0.050 & $2.41^{\mathrm{a}}$ & 0.748
\end{tabular}

${ }^{\mathrm{ab}}$ Means within a column with a common superscript do not differ significantly (p>0.05). EMM: Estimated Marginal Means. Exp. B: Exponential Beta. 
Table 4. Effect of sex on gastrointestinal parasites prevalence and fecal egg/oocyst count in donkeys in Maseru District, Lesotho.

\begin{tabular}{ll|c|c|c|c}
\hline \multirow{2}{*}{ Sex } & & \multicolumn{2}{|c|}{ Prevalence } & \multicolumn{2}{c}{ Fecal egg/oocyst count } \\
\cline { 3 - 6 } & & $\%$ & Standard error & EMM & Standard error \\
\hline \multirow{2}{*}{ Nematodes } & Male & $86.10^{\mathrm{a}}$ & 0.018 & $592.92^{\mathrm{a}}$ & 40.347 \\
& Female & $89.40^{\mathrm{a}}$ & 0.016 & $634.58^{\mathrm{a}}$ & 30.650 \\
\hline \multirow{2}{*}{ Coccidia } & Male & $4.40^{\mathrm{a}}$ & 0.11 & $4.86^{\mathrm{a}}$ & 1.704 \\
& Female & $4.20^{\mathrm{a}}$ & 0.11 & $6.11^{\mathrm{a}}$ & 1.852 \\
\hline \multirow{2}{*}{ Cestodes } & Male & $2.50^{\mathrm{a}}$ & 0.060 & $2.92^{\mathrm{a}}$ & 1.255 \\
& Female & $0.60^{\mathrm{b}}$ & 0.050 & $0.69^{\mathrm{b}}$ & 0.566
\end{tabular}

${ }^{\mathrm{ab}}$ Means within a column with a common superscript do not differ significantly (p>0.05). EMM: Estimated Marginal Means. Exp.B: Exponential Beta.

\section{DISCUSSION}

The higher prevalence of nematodes recorded in the present study was in accordance with the findings of Asefa and Dulo (2017) who observed an overall prevalence of $83.70 \%$ in Bishoftu town, Ethiopia. Different studies conducted in several countries observed a range of 2- 80\% E. leuckarti widespread, for instance, the prevalence ranged $4.5-5.88 \%$ in Turkey (Studzińska et al., 2008), which is close to the overall prevalence of coccidia (4.31\%) observed in the present study. In line with the observations of the current study, Nakayima et al. (2017) found the occurrence of gastrointestinal cestodes to be less in donkeys. However, Belay et al. (2016) recorded a prevalence of $3.7 \%$ of cestodes as compared to $1.53 \%$ observed in the current study.

The higher nematode prevalence and fecal egg count in the donkeys of highlands might be due to grazing on wetlands which have the potential of promoting nematode development due to high moisture content since the annual mean rainfall is between 1000 to $1300 \mathrm{~mm}$ in this region (Olaleye et al., 2016). Raza et al. (2007) also showed that most green pastures that are waterlogged increase the spread of helminths. Similarly, higher mean egg per gram of feces was recorded in donkeys in the highlands (Sheferaw and Alemu, 2015). Development and survival of the nematode eggs and larvae are influenced mainly by climatic conditions, such as temperature and humidity, which differ greatly according to geographical locations (Belete and Derso, 2015).

The high prevalence and level of infection of coccidia in the highlands might be due to poor animal husbandry. Other researchers noted that the occurrence of coccidiosis is associated with undernourishment, poor sanitation, overstocking, poor management practices, and stress (Sudan et al., 2013). Therefore, the lower fecal oocyst count in the lowlands could be attributed to an unfavorable environment for the development of the oocysts because the lowlands are very dry with high temperatures.

The gastrointestinal cestodes were the lowest prevalence in the current study. Tolossa (2016) explained that low prevalence could be due to the seasonality of oribatid mites as vectors. However, in this study, the higher prevalence and intensity of cestodes in the foothills could be due to the longer grazing periods which result in the ingestion of more mites and hence increased cestodes prevalence (IhIer et al., 1995). Moisture is of great importance in increasing the mite population which favors the cestodes infection (Tomczuk et al., 2017). Given the meteorological data, the higher rainfall (900-1000 mm) in the foothills (Olaleye et al., 2016) results in high moisture which contributes to oribatid mites and hence the prevalence of cestodes.

The GIPs affect equines of all ages, although the older equines are likely to develop resistance and act as the source of infection by contaminating the pastures (Shite et al., 2015). There was a significant association between age and the nematode fecal egg load whereby high intensity was in adults probably due to poor body condition. The poor body condition and decreased immunity in adult equines are the results of extensive work, overload, and poor nutritive feeds (Takele and Nibret, 2013; Belay et al., 2016). These adult working donkeys sometimes remain the source of infection to young donkeys because most of them are heavily infected with GIPs without showing any signs of infection. In addition, the lower level of nematode infection in young donkeys may be due to the fact that they are kept in stables most of the time while adults work as pack animals moving from one area to another and this exposes adult donkeys to different parasites. However, Andarge et al. (2017) observed that in terms of susceptibility to nematodes there was no significant difference between young and adult donkeys. On the other hand, the prevalence of Parascaris equorum (nematode) was found to be significantly higher in younger equines (Sheferaw and Alemu, 2015).

The findings of the current study were in accordance with Dubey and Bauer (2018) who observed a higher prevalence of coccidia in foals than that in adult animals and further indicated that foals can acquire infection on the day of birth due to a contaminated environment than being infected from oocysts excreted by their mares. It is emphasized 
that Eimeria leuckarti is more prevalent among young foals though it can be infrequently detected in adult animals (De Souza et al., 2009). Nakayima et al. (2017) stated that the infection of coccidia is related more to young donkeys.

Concerning cestodes, Getachew (2006) also showed that there is no association between age and tapeworm infection prevalence in horses. Sori et al. (2017) indicated that sex was not associated with the prevalence of equine strongylosis, possibly because the management is the same regardless of the sex class (Tone et al., 2016). The insignificant difference in nematode egg counts between male and female donkeys could be due to the fact that they were reared and grazed on the same pasture (Tone et al., 2016). However, Sheferaw and Alemu (2015) stated that $P$. equorum was highly prevalent in female equids than males. Females have a close relationship to their foals, so this makes the females more susceptible as the parasites recycle between dams and foals. Moreover, the possible explanation for nonsignificant differences in terms of GIP infection prevalence and intensity between male and female donkeys could be attributed to the mutual grooming behavior of donkeys that could play a role in transmitting the infection between members of a herd. On the other hand, there are reported cases of the high prevalence of strongylosis in males compared to females despite the fact that the differences were not significant (Sori et al., 2017). The possible reason might be due to the workload done by males than females, which causes stress and consequent immune-suppression which results in parasitic burden (Regassa and Yimer, 2013). In accordance with the results of the present study, other researchers observed equal prevalence of E. leuckarti (coccidia) in both males and females (Ghahfarrokhi et al., 2014). On the other hand, E. leuckarti infection was found to be prevalent in females (De Souza et al., 2009). This explains why there was a higher mean fecal oocyst count in females than males in the current study. However, the obtained results of the present study were in contradiction with that of Nakayima et al. (2017) who found higher mean fecal oocysts count in males than females.

In agreement with the results of the present study, Tomczuk et al. (2017) reported a higher prevalence of cestodes infection in females than that in males. However, Getachew (2006) reported the non-significant difference in the prevalence of cestodes between donkeys from different sexes.

\section{CONCLUSION}

Nematodes were the main gastrointestinal parasites affecting donkeys in the Maseru district. The donkeys in the highlands and adult donkeys were more heavily infected with nematodes. The coccidia prevalence and fecal oocyst load were not affected by the age and sex of the donkeys. The cestodes were more prevalent in male donkeys than females. Therefore, there is a need to develop a deworming strategy addressing specific gastrointestinal parasites for different age and sex groups of donkeys in different agro-ecological zones of Lesotho.

\section{DECLARATIONS}

\section{Authors' contribution}

Masara Elizabeth Nts'aoana conducted the study, analyzed the data, performed laboratory experiments, and wrote the manuscript. Setsumi Mots'oene Molapo conceptualized the study, reviewed, and edited the manuscript. Paseka Kompi analyzed the data and performed laboratory experiments. All authors read and approved the results of study and final manuscript.

\section{Competing interests}

The authors declare no conflict of interest.

\section{Acknowledgments}

The World Horse Welfare (WHW) is acknowledged for providing transport during data collection.

\section{REFERENCES}

Andarge B, Muhammed C, and Tibesso G (2017). Prevalence of major intestinal nematodes of equines in Jimma Town, South Western Ethiopia. International Journal of Veterinary Sciences and Research, 3(2): 69-73. DOI: http://www.dx.doi.org/10.17352/ijvsr.000024

Asefa S, and Dulo F (2017). A Prevalence of gastrointestinal nematode parasitic infections in horses and donkeys in and around Bishoftu Town, Ethiopia. Middle-East Journal of Applied Sciences, 3(3): 38-43. DOI: https://www.doi.org/10.5829/idosi.mejas.2017.38.43

Belay W, Teshome D, and Abiye A (2016). Study on the prevalence of gastrointestinal helminths infection in equines in and around Kombolcha. Journal of Veterinary Science and Technology, 7(5): 367-372. DOI: https://www.doi.org/10.4172/2157$\underline{7579.1000372}$

Belete S, and Derso S (2015). Prevalence of major gastrointestinal parasites of horses in and around Mekelle (Quiha and Wukro). 


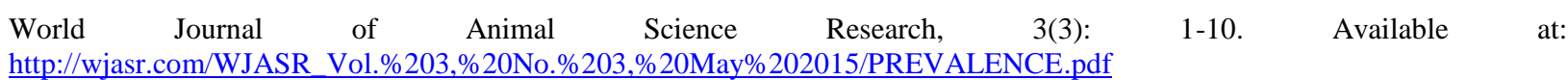

Demelash K, Abebaw M, Negash A, Alene B, Zemene M, and Tilahun M (2016). A review on diagnostic techniques in veterinary helminthology helminthlogy. Nature and Science, 14(7): 109-118. DOI: http://www.doi.org/10.14202/vetworld.2018.1298-1306

De Souza PNB, Bomfim TCB, Huber F, Abboud LCS, and Gomes RS (2009). Natural infection by Cryptosporidium sp., Giardia sp. and Eimeria leuckarti in three groups of equines with different handlings in Rio de Janeiro, Brazil. Veterinary Parasitology, 160: 327-333. DOI: https://www.doi.org/10.1016/j.vetpar.2008.10.103

Dubey JP, and Bauer C (2018). A review of Eimeria infections in horses and other equids. Veterinary Parasitology, 256: 58-70. DOI: https://www.doi.org/10.1016/j.vetpar.2018.04.010

Enigidaw S, Assefa A, Mekonnen N, and Belete S (2015). Prevalence of gastro intestinal nematode parasitic infections of horses and donkeys in and around Kombolcha town. American-Eurasian Journal of Scientific Research, 10: 228-234. DOI: https://www.doi.org/10.5829/idosi.aejsr.2015.10.4.95266

Food and Agricultural Organisation (FAO) (1996). Plant genetic resources, Ministry of Agriculture Lesotho. Available at: http://www.fao.org/fileadmin/templates/agphome/documents/PGR/SoW1/africa/LESOTHO.PDF

Getachew MA (2006). Endoparasites of working donkeys in Ethiopia: Epidemiological study and mathematical modelling [Doctoral dissertation]. University of Glasgow. Available at: http://theses.gla.ac.uk/id/eprint/1444

Ghahfarrokhi EK, Ahmadi AMIN, Shahraki SG, and Azizi H (2014). Eimeria leuckarti (Flesch, 1883; Reichenow, 1940) from worker horses and donkeys of Shahrekord, Iran. International Journal of Advanced Biological and Biomedical Research, 2(6): 19801984. Available at: http://www.ijabbr.com/article_7391_8fa5dc3f64f8ce910bb046744772f8685.pdf.

IhIer CF, Rootwelt V, Heyeraas A, and Dolvik NI (1995). The prevalence and epidemiology of Anoplocephala perfoliata infection in Norway. Veterinary Research Communications, 16(6): 487-494. DOI: https://www.doi.org/10.1007/BF01839337

Molla B, Worku Y, Shewaye A, and Mamo A (2015). Prevalence of strongyle infection and associated risk factors in equine in Menz Keya Gerbil District, North-Eastern Ethiopia. Journal of Veterinary Medicine and Animal Health, 7(4): 117-121. DOI: https://www.doi.org/10.5897/JVMAH2014.0354

Nakayima J, Kabasa W, Aleper D, and Okidi D (2017). Prevalence of endo-parasites in donkeys and camels in Karamoja sub-region, North-eastern Uganda. Journal of Veterinary Medicine and Animal Health, 9(1): 11-15. DOI: https://www.doi.org/10.5897/JVMAH2016.0499

Olaleye AO, Tambi E, Bangali S, and Odularu GOA (2016). Likoti farming under changing climate in Lesotho: Agronomic Grain Yield versus Technical Efficiency. Journal of Ecosystem and Ecography, 5: 2-7. DOI: https://www.dx.doi.org/10.4172/21577625.S5- 001

Raza MA, Iqbal Z, Jabbar A, and Yaseen M (2007). Point prevalence of gastrointestinal helminthiasis in ruminants in southern Punjab, Pakistan. Journal of Helminthology, 81(3): 323-328. DOI: https://www.doi.org/10.1017/S0022149X07818554

Regassa A, and Yimer E (2013). Gastrointestinal parasites of equine in South Wollo zone, North Eastern Ethiopia. Global Veterinaria, 11(6): 824-830. DOI: https://www.doi.org/10.5829/idosi.gv.2013.11.6.76207

Saeed MA, Beveridge I, Abbas G, Beasley A, Bauquier J, Wilkes E, Jacobson C, Hughes KJ, El-Hage C, O’Handley R et al. (2019). Systematic review of gastrointestinal nematodes of horses from Australia. Parasites and Vectors, 12(1): Article number 188. DOI: https://www.doi.org/10.1186/s13071-019-3445-4

Sheferaw D, and Alemu M (2015). Epidemiological study of gastrointestinal helminths of equines in Damot-Gale district, Wolaita zone, Ethiopia. Journal of Parasitic Disease, 39(2): 315-320. DOI: https://www.doi.org/10.1007/s12639-013-0352-z

Shite A, Admassu B, and Abere A (2015). Large strongyle parasites in equine: A review. Advances in Biological Research, 9(4): 247252. DOI: https://www.doi.org/10.5829/idosi.abr.2015.9.9559

Sori G, Bekele T, Geso G, Ibrahim H, Gobena F, Jarso G, Melaku M, and Shumet A (2017). Prevalence of equine strongyle infection and its associated risk factors in Jimma Town, Southwest Ethiopia. International Journal of Livestock Production, 8(11): 187191. DOI: https://www.doi.org/10.5897/IJLP2016.0325

Studzińska MB, Tomczuk KR, and Sadzikowski AB (2008). Prevalence of Eimeria leuckarti in young horses and usefulness of some coproscopical methods for its detection. Bulletin - Veterinary Institute in Pulawy, 52: 541-544. Available at: http://yadda.icm.edu.pl/yadda/element/bwmeta1.element.agro-5b70c8bf-156b-4ce0-95ae-8025679948bd

Sudan V, Sharma RL, Gupta SR, and Borah MK (2013). Successful therapeutic management of concurrent subclinical Eimeria leukarti and Babesia (Theileria) equi infection in a mare. Journal of Parasitic Diseases, 37(2): 177-180. DOI: https://www.doi.org/10.1007/s12639-012-0156-6

Takele B, and Nibret E (2013). Prevalence of gastrointestinal helminthes of donkeys and mules in and around Bahir Dar, Ethiopia. Ethiopian Veterinary Journal, 17(1): 13-30. DOI: https://www.doi.org/10.4314/evj.v17i1.2

Tedla M, and Abichu B (2018). Cross-sectional study on gastro-intestinal parasites of equids in South-western Ethiopia. Parasite Epidemiology and Control, 3(4): e00076. DOI: https://www.doi.org/10.1016/j.parepi.2018.e00076

Tesfu N, Asrade B, Abebe R, and Kasaye S (2014). Prevalence and risk factors of gastrointestinal nematode parasites of horse and donkeys in hawassa town, Ethiopia. Journal of Veterinary Science and Technology, 5(5): 2157-7579. DOI: https://www.dx.doi.org/10.4172/2157-7579.1000210

Tolossa YH (2016). Gastro-intestinal parasites of equines in Tiyo district of Oromia Region, Ethiopia. Global Veterinaria, $17(2)$ : 154 160. DOI: https://www.doi.org/10.5829/idosi.gv.2016.17.02.10468

Tomczuk K, Grzybek M, Szczepaniak K, Studzińska M, Demkowska-Kutrzepa M, Roczeń-Karczmarz M, Abbass ZA, Kostro K, and Junkuszew A (2017). Factors affecting prevalence and abundance of A. perfoliata infections in horses from south-eastern Poland. Veterinary Parasitology, 246: 19-24. DOI: https://www.doi.org/10.1016/j.vetpar.2017.08.027

Tone T, Basaznew B, and Shimels T (2016). Prevalence of major gastrointestinal nematode parasites of donkeys in selected districts 
of Wolaitazone, Southern Ethiopia. Advances in Biological Research, 10(6): 360-364. DOI: https://www.doi.org/10.5829/idosi.abr.2016.360.364

Upjohn MM, Shipton K, Lerotholi T, Attwood G, and Verheyen KL (2010). Coprological prevalence and intensity of helminth infection in working horses in Lesotho. Tropical Animal Health and Production, 42(8): 1655-1661. DOI: https://www.doi.org/10.1007/s11250-010-9617-Z

Waqas M, Nawaz M, Sajid M, Ahmad Z, Mushtaq A, Jabbar A, and Zubair M (2015). Strongylosis (red worms' infestation); a potential threat to donkey's health and performance. Global Veterinaria, 14(3): 345-350. DOI: https://www.doi.org/10.5829/idosi.gv.2015.14.03.9340

Zajac AM, and Conboy GA (2012). Veterinary clinical parasitology. John Wiley and Sons. 8th Edition, UK, pp. 8-11. Available at: https://www.wiley.com/en-us/Veterinary+Clinical+Parasitology\%2C+8th+Edition-p-9780813820538

Zerihun A, Bersissa K, Bojia E, Ayele G, Tesfaye M, and Etana D (2011). Endoparasites of donkeys in Sululta and Gefersa districts of central Oromia, Ethiopia. Journal of Animal and Veterinary Advances, 10(14): 1850-1854. DOI:

https://www.doi.org/10.3923/javaa.2011.1850.1854 